\title{
Finding the Adequate Location Scenario After the Merger of Fire Brigades Thanks to Multiple Criteria Decision Analysis Methods
}

\author{
Mohammad Aldabbas*, Francesca Venteicher*, \\ Lenna Gerber*, Marino Widmer**
}

\begin{abstract}
This paper addresses the issue of selecting a suitable location for a fire station in canton of Fribourg, as a result of a fire brigades' merger, by applying Multiple Criteria Decision Analysis (MCDA) methods. Solving the problem of determining fire station locations through various methods has been analyzed in-depth by researchers. However, a different approach, based on application of ELECTRE I and ELECTRE II methods is advanced in this paper.

The selection of the most suitable fire station site is obtained by applying the designated methods to five distinctive alternatives (called scenarios), taking into consideration the relatively limited information and specifics, and the extensive number of relevant criteria that summed up to sixty-one.

Taking the merger of the three local fire departments as an example, the proposed methods for selecting a suitable location for the fire station demonstrate and justify the reason behind this choice. Research shows that the applied methods have been proven to be useful and powerful tools that exhibited acceptable levels of consistency when selecting the best project. The main finding is that one scenario in particular proved to be preferred over the others and most suitable in determining the fire station location.
\end{abstract}

Keywords: Multiple Criteria Decision Analysis (MCDA), ELECTRE, criteria, weights, alternative evaluation, ranking, fire station location, merger.

\section{Introduction}

Presently in Switzerland, in most municipalities, firefighting and personal rescue are carried out by a fire brigade. If some cities have professionals among their firefighters, villages cannot afford such a costly structure and must rely on volunteer firefighters. Unfortunately, recruiting volunteers is becoming increasingly difficult as their number is steadily declining.

In the canton of Fribourg, the local government is currently encouraging municipalities to regroup their forces through mergers. Thus, over the span of two decades, the number of

* University of Fribourg, DIUF - DS\&OR, Pérolles 90, 1700 Fribourg, Switzerland

** University of Fribourg, DIUF - DS\&OR, Pérolles 90, 1700 Fribourg, Switzerland, marino.widmer@unifr.ch 
municipalities in the canton decreased from 246 in 1997 to 136 in 2017 [12]. In the event that a merger is not planned in the short term, ECAB ${ }^{1}$ (Etablissement cantonal d'assurance des bâtiments du canton de Fribourg) has the task of proposing a collaboration agreement or even a merger between the fire brigades of geographically proximate municipalities.

However, the collaboration or the merger may generate problems: on one hand, the need to coordinate practices that are sometimes different (operating like in the "good old days", different type of management for each fire brigade, location of fire stations). On the other hand, other problems are highlighted, such as a lack of documentation concerning the processes in place, a complete absence of job specifications or a merger proposal without official guidelines.

This paper focuses on the fire station location problem. In the case of a collaboration agreement or a merger, is it necessary to maintain the existing infrastructure, which may generate unnecessary costs, or do new alternatives have to be analyzed in order to be more efficient? Among the different alternatives, at least two scenarios may be highlighted: the one fire station (all-in-one) and new and existing fire stations (old-new mix). The main objective of this paper is to apply two different ELECTRE methods and to compare the outcome.

The reminder of the paper is organized as follows: after a brief state of the art of the literature dealing with the fire station location problem in Section 2, the methodology for defining and choosing the best alternative is described in Section 3. As this selection process is a typical Multi-Criteria Decision Analysis (MCDA) problem, Section 4 is dedicated to a brief overview of two ELECTRE methods. Section 5 details the main steps of the MCDA approach implemented to solve the fire station location problem for the specific collaboration case of the fire departments of three municipalities of Sarine district (Avry, Matran and Neyruz) and introduces the best scenario retained. A set of observations is presented in Section 6. Finally, Section 7 contains the conclusion.

\section{State of the art}

In this section, a literature review will briefly present the main methods applied for solving the problem of determining fire station location (see the synthesis provided in Table 1), with a specific attention for AHP and GIS.

AHP (Analytic Hierarchy Process) is a mathematical MCDA method that derives ratio scales from paired comparison of criteria and allows for some small inconsistencies in judgments. It is possible to use measurements or subjective opinions as inputs for this method. More details on the AHP can be found in Goepel [14]. Di Matteo, Pezzimenti and Garcia [9] applied a hybrid type method, AHP-ELECTRE, in order to simulate the need to build a new fire barrack. While AHP approach is appropriate for quantifying a combination of qualitative information and quantitative data, the GIS deals with geospatial data that provides complementary relevant information to decision makers.

1 Etablissement cantonal d'assurance des bâtiments (ECAB) is the legal authority responsible for insuring all the buildings in the canton of Fribourg and promoting the prevention and defense against fire and natural elements. http://www.ecab.ch/ecab/fr/pub/ecab.htm 
GIS (Geographic Information System) is a widely accepted and popular system put into service in several domains such as determining optimal geographic locations, navigation, global mapping, disaster management, etc. This system is utilized to save, visualize, analyze and display data linked to locations on Earth. Some portion of the input data is spatial (geographic location on the earth) and some is non-spatial attribute data (descriptive or numeric information about each of the spatial features). By combining all sorts of data and multiple layers of information, the GIS system is able to generate a single map. The interested reader can find additional information in ESRI [11] and Dempsey [8]. Several scientific papers focused on GIS in determining locations: Lincoln Fire \& Rescue [18] drew on GIS location allocation analysis, maps and spatial information technologies in station optimization study; Chevalier, Thomas, Geraets, Goetghebeur, Janssens, Peeters and Plastria [5] used GIS together with risk modeling approach for locating fire stations in Belgium and Şen, Önden, Gökgöz and Şen [30] implemented a GIS approach to fire station location selection in Antalya.

Table 1. Overview on the various solution approaches

\begin{tabular}{|c|c|}
\hline References & Solution approaches \\
\hline Kanellakos [16] & $\begin{array}{l}\text { Sophisticated methodology tool called ArcGIS Spatial Analyst in a study on the } \\
\text { location of Ottawa fire stations. }\end{array}$ \\
\hline Kolesar and Walker [17] & $\begin{array}{l}\text { Computer based method and heuristic method for the dynamic relocation of fire } \\
\text { companies in New York City. }\end{array}$ \\
\hline Murray [20] & $\begin{array}{l}\text { Several modeling approaches to optimize the spatial location of urban fire } \\
\text { stations. }\end{array}$ \\
\hline Nourozi and Shariati [21] & Linear assignment method for locating fire stations in Maku City. \\
\hline Richard [22] & $\begin{array}{l}\text { Preliminary analysis applying the p-median method for the fire stations } \\
\text { locations in the province on Luxembourg (Belgium). }\end{array}$ \\
\hline Schreuder [29] & $\begin{array}{l}\text { Road network approach, set covering approach and simulation in the application } \\
\text { of a location model to fire stations in Rotterdam. }\end{array}$ \\
\hline Voller and Curtin [31] & $\begin{array}{l}\text { Spatial analysis methodology (in two phases) for the relocation of Metropolitan } \\
\text { Fire and Emergency Services Board (MFB) fire stations in Melbourne. }\end{array}$ \\
\hline $\begin{array}{l}\text { Yang, Jones and Yang } \\
\text { [34] }\end{array}$ & $\begin{array}{l}\text { Fuzzy multi-objective programming for optimization of fire station locations } \\
\text { through genetic algorithms. }\end{array}$ \\
\hline \multicolumn{2}{|c|}{ Multiple criteria oriented approaches } \\
\hline $\begin{array}{l}\text { Badri, Mortagy and } \\
\text { Alsayed [3] }\end{array}$ & $\begin{array}{l}\text { Multi-criteria modeling approach to locate fire stations via integer goal } \\
\text { programming, using conflicting criteria. }\end{array}$ \\
\hline $\begin{array}{l}\text { Degel, Rachuba, Werners } \\
\text { and Wiesche [7] }\end{array}$ & $\begin{array}{l}\text { Multi-criteria approach MILP (mixed integral linear programming) for the } \\
\text { location of fire departments. }\end{array}$ \\
\hline Granito and Granito [15] & $\begin{array}{l}\text { Weighted scoring of alternatives against selected criteria to choose the location } \\
\text { of the Nantucket central fire station. }\end{array}$ \\
\hline
\end{tabular}

Some studies combined both GIS and AHP methods: Erden and Coşkun [10] in a multicriteria site selection for fire services in Istanbul, Dashti Wahab and Hawta Khayyat [6] in 
modeling the suitability analysis to establish new fire stations in Erbil, and Wei, Li, Lui, Chen and Cui [33] in studying and implementation of fire sites planning.

This review shows that there is not any dominant applied method to be used for fire station location problem. However, multiple criteria modeling seems appealing for most studies.

As the problem addressed in this paper is clearly a problem of multi criteria analysis (see Section 3: Context and Methodology), the choice of applying outranking methods for finding a solution is quite natural. In consequence, the ELECTRE family of methods will be briefly described in Section 4: Methods Overview.

\section{Context and Methodology}

The fire departments of Avry, Matran, and Neyruz witnessed an unprecedented level of collaboration during the past years. Given the significant reduction in staff numbers across the fire departments in Fribourg canton, ECAB proposes, through the FriFire ${ }^{2}$ reform, a merger into a single inter-municipal fire brigade with a sole operating and investment budget. In order to enhance efficiency, as well as centralization of management and control, a merger project between the fire departments of the three municipalities is suggested (CSPi M.A.N. being the name of the new entity). Another motive for the merger is to reduce the workload. Presently the same administrative activities are performed at the level of each municipality, while this could be reduced to single intervention by the municipality in charge of accounting and financial matters.

Nonetheless, one of the arising problem and challenge of the proposed merger is the location of the fire stations (if a new location is required at all). Currently, each municipality has its own fire station, but what would be the optimal number of fire stations after the merger? And where should these stations be located? This paper seeks to answer this question and solve the problem for the new potential location for the fire station(s) under many different weighted criteria. To do so, different scenarios (or alternatives) will be tested and evaluated against all related criteria using the following steps:

1) Define the scenarios, e.g. set up a new location and abandon the old stations, or retain one station and build a new station.

2) Define main categories of criteria that are essential for the location (like establishment costs or technical criteria) and the relevant sub-categories (like acquisition costs, development costs, location, response time). Define the criteria associated to subcategories, like the acquisition costs of land or of an existing building.

3) Assign weights for all criteria, considering that criteria do not have the same importance. For instance, security criteria and response time are much more important than aesthetical concerns.

4) Develop a program to solve the problem using direct MCDA tools for ELECTRE family.

2 The main objective of the FriFire reform is to regionalize the fire defense and to concentrate the resources. A strong constraint is a response time within 15 minutes since a fire alarm is acknowledged with a minimum of 8 firefighters. 
5) Rank the preference of all scenarios according to the solutions obtained from the applied methods and draw a conclusion.

Notice that, if the word "alternative" is commonly used in the MCDA literature, the word "scenario" is preferred here, as a scenario may contain sometimes more than one action, which is not often the case with an alternative.

\section{ELECTRE I and ELECTRE II Overview}

The methods that are briefly described in this paper are ELECTRE I and ELECTRE II of the ELECTRE family. It is called "family" as it groups together a set of related methods (see Table 2). The ELECTRE family was developed by Roy and associates in the mid '60s [23]. The starting point for these methods is the matrix that shows the performance of all alternatives against all criteria taking into consideration the weights of criteria. ELECTRE I generates concordance and discordance matrices where alternatives are the axis, then concordance and discordance thresholds are decided to determine the preference of alternatives over each other.

Table 2. Overview of ELECTRE family methods

\begin{tabular}{|l|l|l|}
\hline Methods & References & Characteristics / Specificities \\
\hline \multicolumn{1}{|l|}{ ELECTRE - Elimination Et Choix Traduisant la REalité } \\
\hline ELECTRE I & Roy [23] & $\begin{array}{l}\text { Designed for selection problems: selecting a smallest set of best } \\
\text { alternatives. }\end{array}$ \\
\hline ELECTRE Iv & $\begin{array}{l}\text { Maystre, Pictet and Simos } \\
\text { [19] }\end{array}$ & ELECTRE I with veto threshold (true-criteria). \\
\hline ELECTRE Is & Roy and Skalka [27] & $\begin{array}{l}\text { Generalization of ELECTRE Iv: modeling situation in presence of } \\
\text { inaccurate data (pseudo-criteria). }\end{array}$ \\
\hline ELECTRE II & Roy and Bertier [24] & $\begin{array}{l}\text { Designed for ranking problems: embedded outranking relations } \\
\text { sequence (true-criteria). }\end{array}$ \\
\hline ELECTRE III & Roy [25] & $\begin{array}{l}\text { Designed for ranking problems: fuzzy binary outranking relations } \\
\text { (pseudo-criteria). }\end{array}$ \\
\hline ELECTRE IV & Roy and Hugonnard [26] & $\begin{array}{l}\text { Designed for ranking problems without the use of relative criteria } \\
\text { importance coefficients. }\end{array}$ \\
\hline ELECTRE TRI & $\begin{array}{l}\text { Roy and Bouyssou [28], } \\
\text { Wei [32] }\end{array}$ & $\begin{array}{l}\text { Tool designed to deal with sorting alternatives into ordered } \\
\text { categories (limiting profiles). Method based on boundary actions. }\end{array}$ \\
\hline ELECTRE TRI-B & $\begin{array}{l}\text { Almeida-Dias, Figueira } \\
\text { and Roy [1] }\end{array}$ & $\begin{array}{l}\text { Renaming of ELECTRE TRI to avoid confusion with ELECTRE } \\
\text { TRI-C. }\end{array}$ \\
\hline ELECTRE TRI-C & $\begin{array}{l}\text { Almeida-Dias, Figueira } \\
\text { and Roy [1] }\end{array}$ & $\begin{array}{l}\text { New sorting method that follows a decision aiding constructive } \\
\text { approach: each category is defined by a single reference action } \\
\text { (central profiles). }\end{array}$ \\
\hline
\end{tabular}

In this paper, the weights are assigned by the experts based on their experience and intuitive judgment. The weights do not represent trade-offs. Each alternative is judged 
against each criteria and the scores represented by numerical values together with the weights (both measured on a predefined ordinal scale) are inserted into an initial assessment grid.

ELECTRE methods are based on the assessment of two indices, the concordance and the discordance, defined for each pair of alternatives. A great array of formulas can be used to define the two indices. However, in this study, the concordance index $C(a, b)$ is the quantification of positive arguments that measures the strength of the hypothesis that alternative $a$ is at least as good as alternative $b$. The concordance index for ELECTRE I is calculated as following (derived from Belton and Stewart [4]):

$$
C(a, b)=\frac{\sum_{i \in Q(a, b)} w_{i}}{\sum_{i=1}^{m} w_{i}}
$$

where $Q(a, b)$ is the set of criteria for which $a$ is equal or preferred to $b$ (i.e. $a$ is at least as good as $b$ ). The concordance index is computed by summing up the weights of the criteria for which $a$ is equal of preferred to $b$, and then divided by the sum of all criteria weights. The index takes on values between 0 and 1 . A value of 1 means that $a$ performs at least as well as $b$ on all criteria (so $a$ dominates or is equivalent to $b$ ).

The discordance index $D(a, b)$ is the quantification of negative arguments that measures the strength of evidence against the hypothesis. The discordance index is defined by the following formula:

$$
D(a, b)=\frac{\max _{i \in R(a, b)}\left[w_{i}\left(z_{i}(b)-z_{i}(a)\right)\right]}{\max _{i=1}^{m} \max _{c, d \in A}\left[w_{i}\left|z_{i}(c)-z_{i}(d)\right|\right]}
$$

where $R(a, b)$ is the set of criteria where $b$ is preferred to $a, A$ is the set of all alternatives and $z_{i}(x)$ represents the value of criterion $i$ for alternative $x$. In this case, the discordance index is the maximum weighted value by which $b$ is better than $a$, expresses as a proportion of the maximum weighted difference between any two alternatives on any criterion. It also takes on values between 0 and 1 . A high value indicates that, for at least one criterion, $b$ performs substantially better than $a$, hence providing counter-evidence to the hypothesis that $a$ is preferred to $b$.

Next step is to build an outranking relation. $C^{*}$ and $D^{*}$ represent the concordance and discordance thresholds to be used when determining the preference of alternative $a$ over alternative $b$ if and only if:

$$
C(a, b) \geq C^{*} \text { and } D(a, b) \leq D^{*}
$$

The resulting outranking relations can be translated into a graph, highlighting the preferences (single-headed arrows) or indifferences (double-headed arrows). According to Belton and Stewart [4], the kernel consists in the set of preferred alternatives, i.e. alternatives such that they outrank the others and they are incomparable. It is very important to perform a sensitivity and robustness analysis on the kernel in order to examine the impact on the results when changes in the $C^{*}$ and $D^{*}$ values are performed. However, no difference or preference is provided to help choose the best alternative among them.

ELECTRE II (an updated version of ELECTRE I) aims to produce a ranking of alternatives instead of just providing a set of most preferred alternatives. The method employs two sets of outranking relations considering two different sets of concordance and 
discordance thresholds; namely: strong outranking $\left(C^{*}\right.$ and $\left.D^{*}\right)$ and weak outranking $\left(C^{-}\right.$ and $D^{-}$). The strong outranking adopts strict thresholds, while weak outranking takes on rather moderate thresholds. In order to minimize the likelihood that two alternatives will outrank each other, an additional constraint is added: in addition to $C(a, b) \geq C^{*}$ it is also essential that $C(a, b) \geq C(b, a)$. Strong and weak outrank matrices appear as a result.

Thanks to an exploitation procedure, described in details in Belton and Stewart [4], two initial rankings of the alternatives (called preorders) are established. First, a top-bottom ranking starting with the "best" alternative and moving down to the "worst" one in a descending order and, secondly, a bottom-up ranking beginning with the "worst" alternative and moving up in an ascending order. If both rankings provide the same results, it demonstrates that the ranking is sound. The partial order can be obtained by intersecting the two preorders, and future tuning will provide the complete order.

When more input data can be used such as preference, indifference and veto thresholds, the use of ELECTRE III (a more complex extension of ELECTRE II) is recommended. For more details about these methods, the reader is advised to check Belton and Stewart [4], Figueira, Greco and Ehrgott [13] and Zopounidis and Pardalos [35].

\section{Application of MCDA Approach}

The application of ELECTRE family will be following the five steps of the methodology described previously in Section 3.

\subsection{Scenarios definition}

The managers in charge and the experts have identified five reasonable scenarios for the future implementation of the fire stations. The scenarios are as follows:

Scenario 1: Three fire stations

Retaining the existing 3 fire stations located in each municipality: Avry, Matran and Neyruz. The premises belong to each municipality based on territorial limits.

Scenario 2: Two fire stations

Relocating Matran's firefighters and equipment to Avry. Matran's fire station will be made available to the "Young firemen of Sarine" (Jeunes Sapeurs-Pompiers de la Sarine, JSPS).

The existing premises in Avry will be remodeled in order to accommodate all of Matran's equipment and staff: construction of a new locker-room area, toilets for women, new garage door, etc.

The fire station in Neyruz is kept in place. A respiratory-protection (RP) cell will be installed inside the existing fire station. 


\section{Scenario 3: One fire station}

Relocating the firefighters and the equipment of Matran and Neyruz to Avry. As the existing space is not big enough to accommodate all staff and equipment, an extension is planned. Several options are possible:

Option 1: use extra space from other municipality services located in the same building Option 2: use the whole space from other municipality services located in the same building

Option 3: build an extension of the existing building (other municipality services keep their spaces)

\section{Scenario 4: New fire station}

Construction of a new fire station for the new fire brigade "CSPi M.A.N.”. Determine the optimal service area.

The new fire station should meet all the criteria that were previously studied and selected. If an existing building meets the established criteria, it is possible to consider the acquisition and transformation of this building into a new fire station. Two options are therefore possible:

Option 1: construct a new building

Option 2: acquire an existing surface and transform it accordingly

Scenario 5: New and existing fire stations

Keep one or more existing fire stations and build or acquire a surface for a new fire station that meets the criteria.

The map in Appendix 1 shows the location of the city of Fribourg and the three municipalities. Fribourg's city limit is represented by a dashed line and its fire station site by the encircled " $F$ ", while the area of concern is bordered by a continuous line. The location of the three current fire stations are marked by the encircled " $\mathrm{C}$ " and the encircled "P" represents one of the potential new locations.

\subsection{Criteria definition}

The selection of relevant criteria was not by any means an easy task. Identified criteria fall into six main categories: establishment costs, operating costs, technical criteria, administrative criteria, economic and social criteria, and other criteria. Each of these categories is divided into sub-categories and their associated criteria that bring more indepth information when performing the analysis for selecting a suitable location for a fire station. All projects guarantee a response time of 15 minutes as per the requirements of the FriFire reform.

The complete list of criteria categories and sub-categories, and their associated criteria, followed by a brief description, is presented in Appendix 2. Note that the final number of criteria sums up to 61 . A synthesis of the six main categories and the related sub-categories is highlighted in Table 3. 
Table 3. Main Criteria Categories and Sub-Categories

\begin{tabular}{|l|l|l|l|l|l|}
\hline $\begin{array}{l}\text { Establishment } \\
\text { Costs }\end{array}$ & $\begin{array}{l}\text { Operating } \\
\text { Costs }\end{array}$ & Technical & Administrative & $\begin{array}{l}\text { Economic \& } \\
\text { Social }\end{array}$ & Other \\
\hline Acquisition & $\begin{array}{l}\text { Start-up and } \\
\text { Running }\end{array}$ & Location & Subsidies & $\begin{array}{l}\text { New Fire } \\
\text { Station }\end{array}$ & Professionalism \\
\hline Development & $\begin{array}{l}\text { Intervention } \\
\text { Failure }\end{array}$ & $\begin{array}{l}\text { Transportation } \\
\text { Network }\end{array}$ & Political Matters & $\begin{array}{l}\text { Expansion \& } \\
\text { Adaptations }\end{array}$ & $\begin{array}{l}\text { Effectiveness } \\
\text { \& Efficiency }\end{array}$ \\
\hline $\begin{array}{l}\text { Construction \& } \\
\text { Transformation }\end{array}$ & $\begin{array}{l}\text { Depreciation \& } \\
\text { Amortization }\end{array}$ & $\begin{array}{l}\text { Response } \\
\text { Time }\end{array}$ & Public Opinion & Population & Reliability \\
\hline & & $\begin{array}{l}\text { Coverage \& } \\
\text { Accessibility }\end{array}$ & $\begin{array}{l}\text { Financial } \\
\text { Soundness }\end{array}$ & $\begin{array}{l}\text { Environmen- } \\
\text { tal Issues }\end{array}$ & $\begin{array}{l}\text { Stochasticity \& } \\
\text { Robustness }\end{array}$ \\
\hline & & Risks & & $\begin{array}{l}\text { Economies of } \\
\text { Scale }\end{array}$ & Sustainability \\
\hline
\end{tabular}

\subsection{Weights assignment and projects assessment}

Due to the nature of this project and the large number of stakeholders involved, evaluations for the five scenarios against the 61 criteria should be ideally performed by several specialists. However, in this study, the evaluation of one expert will be considered when applying the solution methods. The expert in question brings his own expertise to the project by his position held at the political level on the municipality council. Other outcomes might be generated if other evaluations are to be taken into account in the future.

The starting point of the analysis is the creation of the assessment grid, categorizing the criteria and assigning a weight to each criterion. The importance of a criterion is graded according to an ordinal scale (non applicable, ..., extremely important) and the value associated with represents the criterion's weight (from 0 to 5). The weighting process takes into the account that each category has different importance (relative percentage with sum of the weights equal to 100), and each criterion has its own weight within its sub-category. Both values are multiplied and divided by 10 to give the relative weight of the criterion. For example, for criterion number 1 , the category weight is 15 and the criterion weight is 3 . The result of the multiplication $15 \times 3=45$ divided by 10 (to keep numbers simpler) equals to 4.5 and represents the relative weight of criterion number 1 . In order to execute the multi criteria analysis, the relative weights are normalized in order to prevent any results inconsistencies. The normalization is done by dividing the relative weight of each criterion by the sum of relative weights of all criteria. Naturally, the sum of normalized values is equal to 1.

The performance of alternatives against each criteria is given by a numerical score which is measured on a preference scale (catastrophic, ..., perfect) that stretches on both sides (from -3 to 3 ) of a central value corresponding to a neutral position (in our case, moderate equals to 0). Naturally, when costs are concerned, "perfect" means that the estimated costs are compatible with the foreseen budget, while "catastrophic" means that the estimated costs are definitively too expensive. Complete details concerning the evaluation guide are shown in Table 4. 
The complete evaluations of all alternatives against all criteria with their normalized weights according to the expert is presented in Appendix 3, while an abstract view of the extension with relative weights is presented in Table 5.

Table 4. Evaluation Guidelines

\begin{tabular}{|l|c||l|c|}
\hline Importance of criterion & Corresponding weight & Performance & Assigned Score \\
\hline Extremely important & 5 & Perfect & 3 \\
\hline Important & 4 & Very good & 2 \\
\hline Average & 3 & Good & 1 \\
\hline Less important & 2 & Moderate & 0 \\
\hline Not important & 1 & Bad & -1 \\
\hline Not applicable & 0 & Very bad & -2 \\
\hline
\end{tabular}

Table 5. Evaluation of Alternatives (abstract)

\begin{tabular}{|l|c|c|c|c|c|c|c|c|c|c|}
\hline \multicolumn{1}{|c}{} & \multicolumn{4}{|c|}{ Scenarios and scores } \\
\hline \multirow{2}{*}{ Category } & $\begin{array}{c}\text { Criterion } \\
\text { Number }\end{array}$ & $\begin{array}{c}\text { Category } \\
\text { Multiple }\end{array}$ & $\begin{array}{c}\text { Criterion } \\
\text { Weight }\end{array}$ & $\begin{array}{c}\text { Relative } \\
\text { Weight }\end{array}$ & $\begin{array}{c}\text { Normalized } \\
\text { Weight }\end{array}$ & $\mathbf{1}$ & $\mathbf{2}$ & $\mathbf{3}$ & $\mathbf{4}$ & $\mathbf{5}$ \\
\hline & 1 & 15 & 3 & 4.5 & 0.01184 & 1 & 1 & 1 & 2 & 1 \\
\hline \multirow{2}{*}{$\begin{array}{l}\text { Establishment } \\
\text { Costs }\end{array}$} & 2 & 15 & 5 & 7.5 & 0.01974 & 0 & 1 & 2 & 1 & 0 \\
\hline & 3 & 15 & 2 & 3 & 0.00789 & -1 & 2 & 2 & -1 & 0 \\
\hline & 4 & 15 & 3 & 4.5 & 0.01184 & 2 & 1 & 1 & 2 & 1 \\
\hline & $\ldots$ & $\ldots$ & $\ldots$ & $\ldots$ & $\ldots$ & $\ldots$ & $\ldots$ & $\ldots$ & $\ldots$ & $\ldots$ \\
\hline
\end{tabular}

\subsection{Software development}

In order to provide a user-friendly tool to municipalities, that will allow to easily bring, when required, changes to scenarios, criteria and weights, the development of an Excel based program has been preferred over the purchase of a commercial software.

This Excel based software contains the following methods: ELECTRE I, ELECTRE II, ELECTRE III as well as PROMETHEE I and PROMETHEE II (not presented in this paper).

\subsection{Finding the best scenario}

Starting from the evaluation of projects (the assessment grid filled in by the expert), it is possible to apply the ELECTRE I method to provide a set of favorable alternatives for the problem. The concordance and discordance matrices for ELECTRE I and ELECTRE II are 
shown in Table 6. The outrank relations and kernel sets with the parameters $C^{*}$ and $D^{*}$ are shown in Figure 1.

By analyzing the results of the assessment grid, it could be deducted that some of the criteria will have very little, if no influence at all on the scenarios' scoring. For example, criterion no. 36 (social and political risks) is not relevant in the actual Swiss geopolitical context due to the country's political and economical stable situation. However, for completeness reasons when applying this concept to other situations, the authors tried to be as exhaustive as possible when defining the 61 criteria. In this study, noticeable as well is the fact that all scenarios obtained the same score according to 12 criteria, which simply means that these 12 criteria will have no specific influence on discriminating the scenarios. In addition, the outcomes of a pair-wise comparison of the scenarios suggests that, by far, scenario 4 is strictly better with respect to 16 criteria, and is at least as good as each other scenario with respect to 22 criteria from the total set of 61 criteria. Consideration is to be given to the fact that no emphasis was made on a particular category of criteria. The analysis shows that Scenario 4 is clearly the dominant solution for almost all sets of concordance and discordance parameters. It is not easy to determine with ELECTRE I the second best alternative since it is not the objective of this method. However, for doing so, Scenario 4 must be deleted from Table 4 and the ranking relations between projects have to be recalculated. Hence, the existence or removal of any alternative in the set will probably impact the final outcome of the analysis, no matter how good or bad it performs.

Table 6. Concordance and Discordance Matrices

\begin{tabular}{|l|c|c|c|c|c|}
\hline Concordance & Scenario 1 & Scenario 2 & Scenario 3 & Scenario 4 & Scenario 5 \\
\hline Scenario 1 & 1.00 & 0.55 & 0.58 & 0.38 & 0.57 \\
\hline Scenario 2 & 0.79 & 1.00 & 0.75 & 0.41 & 0.92 \\
\hline Scenario 3 & 0.76 & 0.73 & 1.00 & 0.55 & 0.76 \\
\hline Scenario 4 & 0.89 & 0.94 & .093 & 1.00 & 0.98 \\
\hline Scenario 5 & 0.80 & 0.89 & 0.75 & 0.39 & 1.00 \\
\hline Discordance & Scenario 1 & Scenario 2 & Scenario 3 & Scenario 4 & Scenario 5 \\
\hline Scenario 1 & 0.00 & 0.32 & 0.40 & 0.40 & 0.40 \\
\hline Scenario 2 & 0.33 & 0.00 & 0.27 & 0.33 & 0.17 \\
\hline Scenario 3 & 0.33 & 0.17 & 0.00 & 0.50 & 0.33 \\
\hline Scenario 4 & 0.17 & 0.12 & 0.12 & 0.00 & 0.04 \\
\hline Scenario 5 & 0.33 & 0.13 & 0.27 & 0.27 & 0.00 \\
\hline
\end{tabular}


Figure 1. Outrank Relations and Kernel Sets
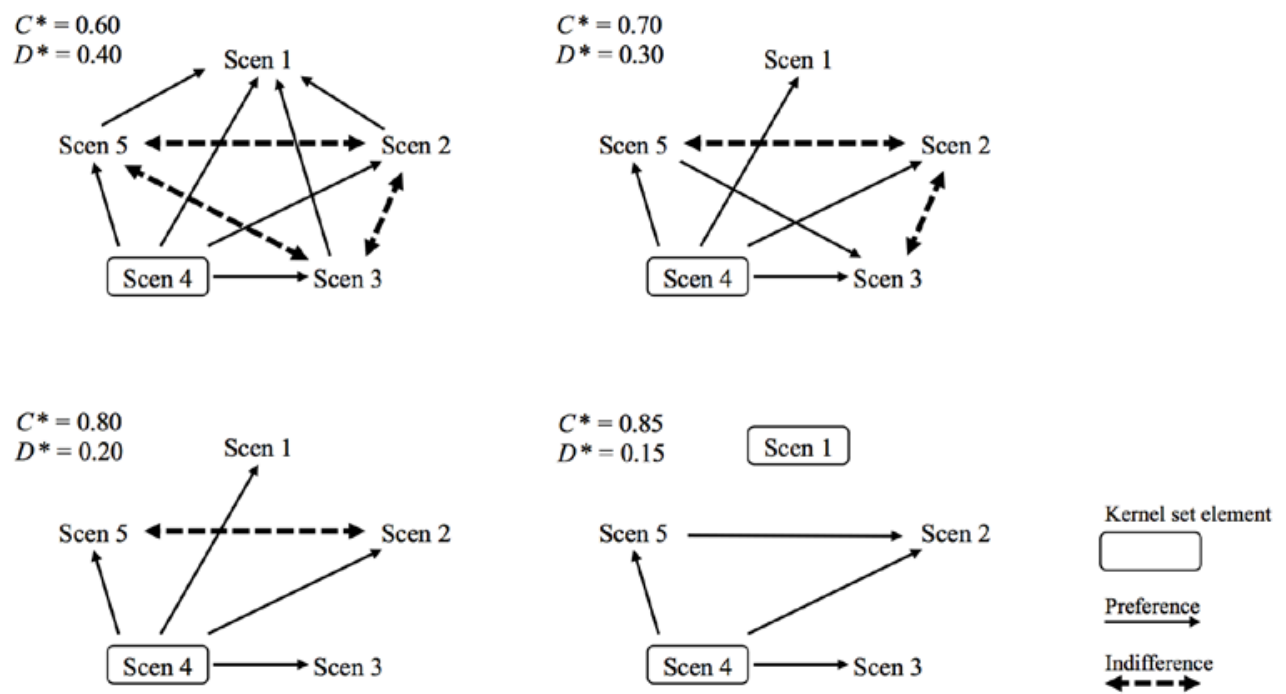

By conducting the analysis for the four scenarios (excluding Scenario 4), the outcomes cannot decide on one dominating solution. For each set of concordance and discordance parameters, a different kernel set was generated, mostly with no difference in between alternatives. This might be due to the close performance of the compared alternatives, and partly to the simplicity of ELECTRE I that allows in its outrank relations a double outrank. This issue was addressed in the later version ELECTRE II.

The final conclusion of ELECTRE I for this problem is that Scenario 4 is the dominant solution with no other preference amongst the remaining alternatives. The use of ELECTRE II is highly recommended.

The starting point of ELECTRE II is the same as in ELECTRE I. The values used are the same like in Table 5 and Table 6 . Strong and weak concordance and discordance thresholds are chosen as follows (additional sets of thresholds are considered in the analysis):

$$
C^{*}=0.80, D^{*}=0.30, \quad C^{-}=0.6, D^{-}=0.40
$$

The strong and weak outrank relations are shown in Table 7. 
Table 7. Strong and Weak Outrank Relations

\begin{tabular}{|l|c|c|c|c|c|}
\hline Strong Outrank & Scenario 1 & Scenario 2 & Scenario 3 & Scenario 4 & Scenario 5 \\
\hline Scenario 1 & 0 & 0 & 0 & 0 & 0 \\
\hline Scenario 2 & 0 & 0 & 0 & 0 & 1 \\
\hline Scenario 3 & 0 & 0 & 0 & 0 & 0 \\
\hline Scenario 4 & 1 & 1 & 1 & 0 & 0 \\
\hline Scenario 5 & 0 & 0 & 0 & 0 & 0 \\
\hline Weak Outrank & Scenario 1 & Scenario 2 & Scenario 3 & Scenario 4 & Scenario 5 \\
\hline Scenario 1 & 0 & 0 & 0 & 0 & 1 \\
\hline Scenario 2 & 1 & 0 & 1 & 0 & 1 \\
\hline Scenario 3 & 1 & 0 & 0 & 0 & 1 \\
\hline Scenario 4 & 1 & 1 & 1 & 0 & 0 \\
\hline Scenario 5 & 1 & 0 & 0 & 0 & 0 \\
\hline
\end{tabular}

Table 8. Ranking of Alternatives ELECTRE II

\begin{tabular}{|c|c|c|c|c|c|c|}
\hline \multicolumn{2}{|c|}{ Threshold Values } & Descending Preorder & Ascending Preorder & Complete Order \\
\hline $\boldsymbol{C}^{*}$ & 0.80 & 0.90 & 0.75 & Scenario 4 & Scenario 4 & Scenario 4 \\
\hline $\boldsymbol{D}^{*}$ & 0.30 & 0.25 & 0.20 & Scenario 2 & Scenario 2 & Scenario 2 \\
\hline $\boldsymbol{C}^{-}$ & 0.60 & 0.65 & 0.55 & Scenario 3 & Scenario 3 & Scenario 3 \\
\hline $\boldsymbol{D}^{-}$ & 0.40 & 0.35 & 0.45 & Scenario 5 & Scenario 5 & Scenario 5 \\
\hline & & & & Scenario 1 & Scenario 1 & Scenario 1 \\
\hline
\end{tabular}

Consequently, the generated two preorders and complete order for the mentioned parameters and other sets of parameters are presented in Table 8. Note that all sets of tested thresholds resulted in the exact orders. This order brings enough evidence that Scenario 4 is the dominant solution followed by Scenario 2 .

The method ELECTRE III is rather too sophisticated (at least for the project under study) and requires a big amount of additional inputs. For instance, it requires a veto threshold value and a preference threshold for each of the 61 criteria used.

\section{Observations}

The application of ELECTRE I and II is relatively easy because the methods are rather simple in terms of calculations and do not require too much inputs and provide a clear preference of alternatives. The ELECTRE I solution is robust only for the most preferred alternative (Scenario 4) but unclear in giving a preference for the remaining alternatives, while the results of ELECTRE II are very direct in their preference, as Scenario 4 being the best alternative followed by the other alternatives as shown in Table 8. Both methods 
suggested the same solution for the problem. Therefore, the final recommendation for the case study is to select Scenario 4: build a new fire station for the new fire brigade and abandon the old stations.

This paper tried to apply relatively simple methods to find the most appropriate solution for the fire station location problem. ELECTRE I and II were not the only methods applied. As mentioned in Section 5.4, the in-house program allows other outranking methods (like ELECTRE III, PROMETHEE I and II) to be tested. Despite the difficulty of their inputs and variables, the three additional methods reach to the same conclusion. Moreover, sensitivity analysis with different threshold values in these non-presented methods did not contradict the solution of ELECTRE I and II. This might be due to two reasons: firstly, these methods (ELECTRE and PROMETHEE) are very similar (according to Belton and Stewart [4]) and secondly, as Scenario 4 performs significantly better than all other alternatives, any evaluation method used would recommend this solution.

\section{Conclusion}

The MCDA approach proved to be possible and efficient to use, especially with limited data available. The various explored methods showed a good level of consistency. One of the most important reasons to use MCDA methods is the possibility and the ease of assigning and using weights for each criterion. ELECTRE I is rather too simple and its outcomes are of limited benefits, while ELECTRE II gave a more comprehensive comparison and possibility to rank the alternatives. In addition, the sensitivity analysis (selecting different sets of thresholds) performed with ELECTRE II proved that the solution is quite robust. This demonstrates that the final recommendation - suggesting Scenario 4 - is the only reasonable and representative solution to the problem.

\section{Acknowledgements}

The authors would like to acknowledge the constructive comments and valuable suggestions of the anonymous reviewers to improve this paper and would like to thank all the stakeholders (from the experts to the local actors) for their contribution to the project.

\section{References}

[1] Almeida-Dias J., Figueira J., Roy B., ELECTRE Tri-C: A multiple criteria sorting method based on characteristic reference actions, European Journal of Operational Research, 204, 3, 2010, 565-580.

[2] Almeida-Dias J., Figueira J., Roy B., A multiple criteria sorting method where each category is characterized by several reference actions: The ELECTRE TRI-nC method, European Journal of Operational Research, 217, 3, 2012, 567—579.

[3] Badri M.A., Mortagy A.K., Alsayed A., A multi-objective model for locating fire stations, European Journal of Operational Research, 110, 2, 1998, 243-260. 
[4] Belton V., Stewart T., Multiple criteria decision analysis: An integrated approach, Kluwer Academic Publisher, Boston, 2002.

[5] Chevalier P., Thomas I., Geraets D., Goetghebeur E., Janssens O., Peeters D., Plastria F., Locating fire stations. An integrated approach for Belgium, Socio-Economic Planning Sciences, 46, 2, 2012, 173-182.

[6] Dashti Wahab S., Hawta Khayyat A., Modeling The Suitability Analysis To Establish New Fire Stations In Erbil City Using The Analytic Hierarchy Process And Geographic Information Systems, Journal of Remote Sensing and GIS, 2, 1, 2014.

[7] Degel D., Rachuba S., Werners B., Wiesche L., Multi-Criteria Covering-Based Location of Volunteer Fire Departments, Ruhr-University Bochum (RUB) Working Paper 2012-01, [Available at SSRN: https://ssrn.com/abstract=2243608].

[8] Dempsey C., What is GIS?, 2017, [Available online https://www.gislounge.com/what-isgis/].

[9] Di Matteo U., Pezzimenti P.M., Garcia D.A., Methodological Proposal for Optimal Location of Emergency Operation Centers through Multi-Criteria Approach, MDPI Sustainability, 16, 8, 2016, 50.

[10] Erden T., Coşkun M.Z., Multi-criteria site selection for fire services. The interaction with analytic hierarchy process and geographic information systems, Natural Hazards Earth System Sciences, 10, 10, 2010, 2127-2134.

[11] ESRI, GIS for Fire Station Locations and Response Protocol, 2007, [Available online https://www.esri.com/library/whitepapers/pdfs/gis-for-fire.pdf].

[12] Etat de Fribourg, Annuaire statistique du canton de Fribourg - Edition 2017, [Available online: http://www.fr.ch/sstat/files/pdf90/annuaire_internet_2017.pdf].

[13] Figueira J., Greco S., Ehrgott M., Multiple Criteria Decision Analysis: State of the Art Surveys, New York, Springer Science + Business Media, Inc., 2005.

[14] Goepel K., What is AHP?, 2013, [Available online https://bpmsg.com/academic/ahp.php].

[15] Granito J., Granito D., Guidelines for Locating the Nantucket Central Fire Station, 2013, [Available online: http://www.nantucket-ma.gov/DocumentCenter/View/1030].

[16] Kanellakos S., Fire Station Location Study - Phase 1. Ottawa Fire Services, 2013, [Available online: http://app06.ottawa.ca/calendar/ottawa/citycouncil/cpsc/2008/0918/ACS2008 -CPS-OFS-0001.htm].

[17] Kolesar P., Walker W.E., An Algorithm for the Dynamic Relocation of Fire Companies, Operations Research, 22, 2, 1974, 249-274.

[18] Lincoln Fire \& Rescue, Station Optimization Study, 2012, [Available online: https://lincoln.ne.gov/city/fire/pdf/relocate/optimum.pdf].

[19] Maystre L., Pictet J., Simos J., Les Méthodes Multicritères ELECTRE, Presses Polytechniques et Universitaires Romandes, Lausanne, 1994.

[20] Murray A.T., Optimising the spatial location of urban fire stations, Fire Safety Journal, 62, 2013, 64-71.

[21] Nourozi S.A., Shariati A.R., Study of Locating Fire Stations using Linear Assignment Method: Case Study Maku City, Global Journal of Human Social Science Research, 13, 3-H, 2013.

[22] Richard D., La localisation des services d'incendie dans la province de Luxembourg: un rapport préliminaire, Recherches Economiques de Louvrain, 48, 3-4, 1982, 219246. 
[23] Roy B., Classement et choix en présence de points de vue multiples (la méthode ELECTRE), La Revue d'Informatique et de Recherche Opérationnelle (RIRO), 8, 1968, 57-75.

[24] Roy B., Bertier P., La méthode ELECTRE II, Note de travail 142, SEMA-METRA, Metra-International, 1971.

[25] Roy B., ELECTRE III: Un algorithme de classements fondé sur une représentation floue des préférences en présence de critères multiples, Cahiers du Centre d'Etudes de Recherche Opérationnelle, 20, 1, 1978, 3-24.

[26] Roy B., Hugonnard J.C., Ranking of suburban line extension projects on the Paris metro system by a multicriteria method, Transportation Research Part A: General, 16, 4, 1982, 301-312.

[27] Roy B., Skalka J.-M., ELECTRE Is: aspects méthodologiques et guide d'utilisation, Document du LAMSADE, 30, Université Paris-Dauphine, Paris, France, 1984.

[28] Roy B., Bouyssou D., Aide multicritère à la décision: méthodes et cas, Economica, Paris, 1993.

[29] Schreuder J.A.M., Application of a location model to fire stations in Rotterdam, European Journal of Operational Research, 6, 2, 1981, 212-219.

[30] Şen A., Önden İ., Gökgöz T., Şen C., A GIS Approach To Fire Station Location Selection, Conference: GI4DM 2011 GeoInformation For Disaster Management, Antalya, Turkey, 2011.

[31] Voller H., Curtin T., Spatial Analysis Methodology for the Relocation of MFB Fire Stations, Proceedings of the Surveying and Spatial Sciences Conference 2011 (SSSC2011), 21-25 November 2011, Wellington, New Zealand, 2011.

[32] Wei Y., Aide multicritère à la décision dans le cadre de la problématique du tri: concepts, méthodes et applications, Thèse de doctorat, Université Paris-Dauphine, Paris, France, 1992.

[33] Wei L., Li H., Lui Q., Chen J., Cui Y., Study and implementation of fire sites planning based on GIS and AHP, Procedia Engineering, 11, 2011, 486-495.

[34] Yang L., Jones B.F., Yang S.-H., A fuzzy multi-objective programming for optimization of fire station locations through genetic algorithms, European Journal of Operational Research, 181, 2, 2007, 903-915.

[35] Zopounidis C., Pardalos P.M., Handbook of multicriteria analysis, Dordrecht, London: Springer (APOP, 103), 2010.

Received 19.03.2018, Accepted 18.05.2018 


\section{APPENDIX 1}

Figure 2. Map of Fribourg and the three municipalities (Avry, Matran and Neyruz)

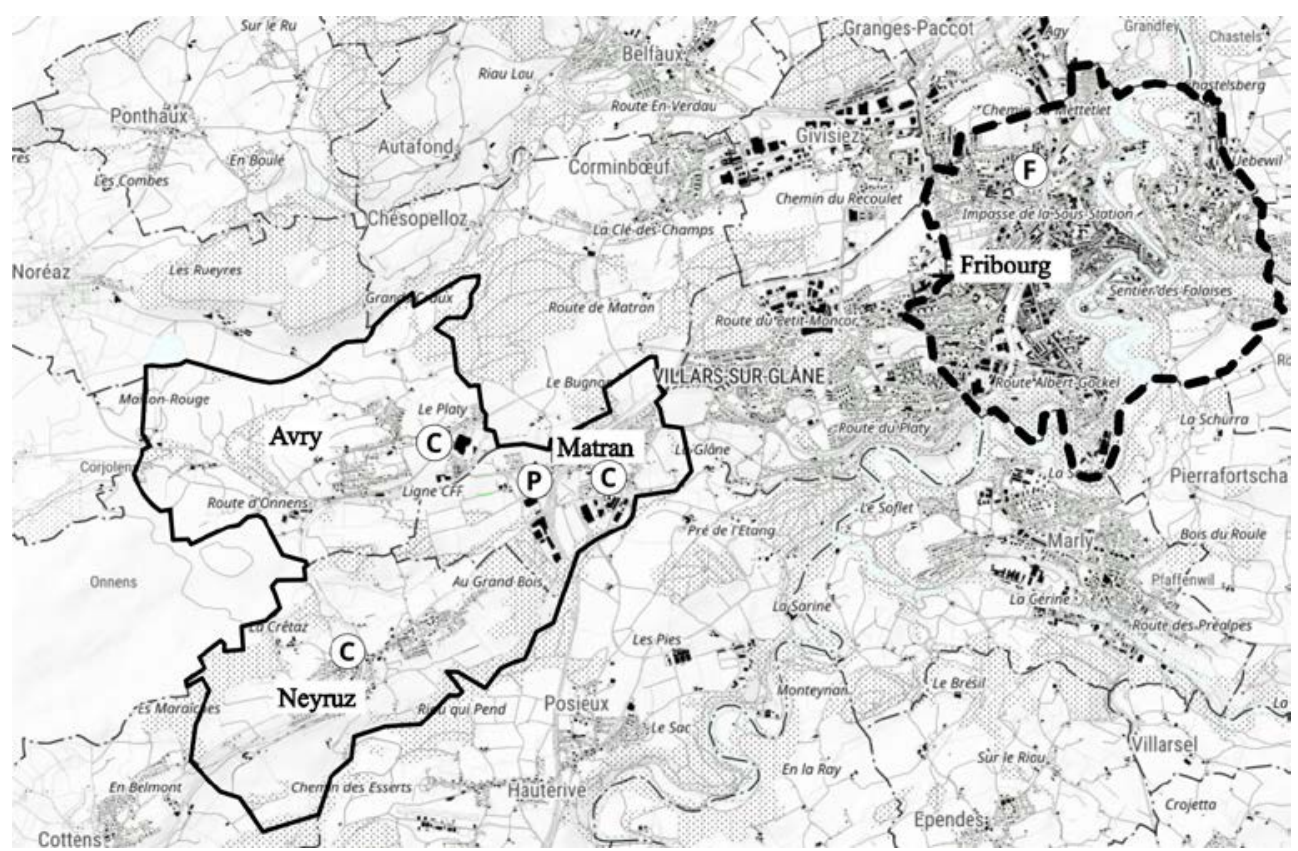
$1 \mathrm{~km}$
Area of project
Current Fire Stations Location (C)
Potential Location
City of Fribourg
Centre de Renfort Fribourg 


\section{APPENDIX 2}

Table 9. Criteria list (A: criterion number, B: criteria category, C: criteria sub-category, D: criteria, E: comments)

\begin{tabular}{|c|c|c|}
\hline A & B C D & $\mathbf{E}$ \\
\hline \multicolumn{3}{|c|}{ 1. Establishment Costs } \\
\hline \multicolumn{3}{|c|}{ 1.1 Acquisition Costs } \\
\hline 1 & 1.1.1 land & cost of land \\
\hline 2 & 1.1.2 existing building & acquisition of an existing building \\
\hline 3 & 1.1.3 various rights & various rights (property, acquisition, legal, etc.) \\
\hline \multicolumn{3}{|c|}{1.2 Development Costs } \\
\hline 4 & 1.2.1 cost of land development and utilities & $\begin{array}{l}\text { all costs associated with land development and utilities } \\
\text { (water, hydrants, sewers, gas, etc.) }\end{array}$ \\
\hline 5 & 1.2.2 construction of access road & all costs associated with construction of access road \\
\hline \multicolumn{3}{|c|}{ 1.3 Construction And Transformation Costs } \\
\hline 6 & 1.3.1 construction costs & $\begin{array}{l}\text { all costs associated with construction (demolishing, building, } \\
\text { etc.) }\end{array}$ \\
\hline 7 & 1.3.2 remodeling costs & all costs associates with remodeling / reconfiguring \\
\hline \multicolumn{3}{|c|}{ 2. Operating Costs } \\
\hline \multicolumn{3}{|c|}{ 2.1 Start-Up \& Running Costs } \\
\hline 8 & 2.1.1 personnel (staff) costs & staff needed to perform all the duties \\
\hline 9 & 2.1.2 material \& equipment (M\&E) costs & M\&E required by law and special cases \\
\hline 10 & 2.1.3 installation costs & installation / relocation costs for staff and M\&E \\
\hline 11 & 2.1.4 operating costs & $\begin{array}{l}\text { all operations concerning protection against natural hazards } \\
\text { (flood, snow, earthquake, building resistance to storms, etc.) } \\
\text { and fire detection in the fire station (alarm, sprinklers, etc.) } \\
\text { costs associated with the maintenance of facility and M\&E }\end{array}$ \\
\hline \multicolumn{3}{|c|}{ 2.2 Intervention Failure Costs } \\
\hline 13 & 2.2.1 personal injuries costs & injuries related to interventions, loss of lives \\
\hline 14 & 2.2.2 material \& equipment loss & damage and loss of material \& equipment \\
\hline 15 & 2.2.3 pollution costs & pollution and other environmental hazards \\
\hline 16 & 2.2.4 property damage costs & $\begin{array}{l}\text { damage and loss of personal property (buildings, livestock, } \\
\text { personal belongings, etc.) }\end{array}$ \\
\hline \multicolumn{3}{|c|}{ 2.3 Depreciation Costs \& Amortization } \\
\hline 17 & 2.3.1 costs of assets & costs of all assets \\
\hline 18 & 2.3.2 value decrease of assets & decrease in value of assets \\
\hline 19 & 2.3.3 residual assets value & residual value of assets \\
\hline 20 & 2.3.4 investment life & estimated useful life of assets \\
\hline 21 & 2.3.5 amortization & reducing the financial debt (loans) \\
\hline \multicolumn{3}{|c|}{ 3. Technical Criteria } \\
\hline \multicolumn{3}{|c|}{3.1 Location } \\
\hline 22 & 3.1.1 geographical barriers & $\begin{array}{l}\text { adequate land based on natural conditions: lake, river, } \\
\text { slope, elevation, soil texture, etc. }\end{array}$ \\
\hline 23 & 3.1.2 public facilities accessibility & $\begin{array}{l}\text { access to public facilities (schools, hospitals, parks, } \\
\text { shopping centers, industrial zones, etc.) }\end{array}$ \\
\hline 24 & 3.1.3 territorial development plan (TDP) & TDP developed and approved by the municipality \\
\hline 25 & 3.1.4 fire station size \& layout & size and capacity of the facility \\
\hline 26 & 3.1.5 proximity to other fire stations & number of other fire stations \& closeness (distance) \\
\hline 27 & $\begin{array}{l}\text { 3.1.6 proximity to municipal services \& } \\
\text { utilities }\end{array}$ & $\begin{array}{l}\text { proximity to municipal services \& required utilities (water, } \\
\text { hydrants, sewers, gas, etc.) }\end{array}$ \\
\hline \multicolumn{3}{|c|}{ 3.2 Transportation Network } \\
\hline 28 & 3.2.1 ease of access to road network & $\begin{array}{l}\text { accessibility, future development of the road network (new } \\
\text { roads, roundabouts, highway entry/exit, etc.) }\end{array}$ \\
\hline 29 & 3.2.2 travel pattern & fluidity of traffic, peak times, level of traffic congestion \\
\hline \multicolumn{3}{|c|}{ 3.3 Response Time $(R T)$} \\
\hline 30 & 3.3.1 max 15 min with 8 firefighters: $80 \%$ & $\begin{array}{l}\text { FriFire report: max. delay of } 15 \mathrm{~min} \text { for at least } 80 \% \text { of } \\
\text { interventions }\end{array}$ \\
\hline 31 & 3.3 .2 over 15 min: $20 \%$ & FriFire report: only in particular circumstances \\
\hline 32 & 3.3.3 call / alarm volume & number of calls / alarms received \\
\hline
\end{tabular}




\begin{tabular}{cc}
\hline & 3.4 Coverage \& Accessibility \\
33 & 3.4 .1 area of response coverage \\
& \\
34 & 3.4 .2 concentration of resources \\
35 & 3.4 .3 accessibility to all sites \\
\hline & 3.5 Risks \\
36 & 3.5 .1 social and political risks \\
37 & 3.5 .2 community risks
\end{tabular}

4. Administrative Criteria 4.1 Subsidies

$\begin{array}{lc}38 & 4.1 .1 \text { subsidies from confederation } \\ 39 & 4.1 .2 \text { subsidies from municipality } \\ 40 & 4.1 .3 \text { subsidies from state / ECAB } \\ 41 & \text { 4.2 Political Matters: Laws \& Regulations } \\ 42 & 4.2 .1 \text { state laws \& regulations } \\ & 4.2 .2 \text { compliance with laws \& regulations }\end{array}$

4.3 Public Opinion

$43 \quad 4.3 .1$ elections

$44 \quad 4.3 .2$ voting

4.4 Financial Soundness

\begin{tabular}{|c|}
$45 \quad 4.4 .1$ financial \& fiscal situation \\
\hline 5. Economic \& Social Criteria \\
\hline 5.1 New Fire Station
\end{tabular}

$46 \quad 5.1 .1$ necessity of a new fire station

5.2 Expansion \& Adaptations

\begin{tabular}{ll}
47 & 5.2 .1 future expansion \& adaptations \\
\hline & 5.3 Population \\
48 & 5.3 .1 population structure \\
50 & 5.3 .2 density \\
51 & 5.3 .3 demographic growth \\
\hline
\end{tabular}

$51 \quad 5.3 .4$ pool of candidates

$52 \quad 5.4 .1$ pollution hazards

$53 \quad 5.4 .2$ health hazards \& effects

\begin{tabular}{lc}
\hline & 5.5 Economies of scale \\
54 & $5.5 .1 \mathrm{M} \&$ E utilization rate \\
55 & 5.5 .2 volume of financial benefits \\
& \\
\hline & 5.6 Other Usages \\
56 & 5.6 .1 other usages
\end{tabular}

\section{Other Criteria}

57 6.1.1 improvement of "professionalism"

\begin{tabular}{cc}
\hline & 6.2 Effectiveness \& Efficiency \\
58 & 6.2 .1 effectiveness \& efficiency \\
\hline \multirow{2}{*}{59} & 6.3 Reliability \\
& 6.3 .1 reliability \\
\hline \multirow{3}{*}{60} & 6.4 Stochasticity \& Robustness \\
& 6.4.1 stochasticity \& robustness
\end{tabular}

coverage of area by time, distance, number of fire \& firstaid units, etc.

concentration of M\&E based on existing fire stations accessibility to all sites within the determined response area

not really applicable (strike, war, etc.)

define risk categories, identification of fire hazards, focal points, time differentials (response-time requirement to each risk vs. straight $\mathrm{km}$ response), etc.

if applicable
if applicable
see ECAB guidelines for subsidies

all laws \& regulations in place concerning the firefighters compliance at municipality level with laws \& regulations

impact of local elections impact of local \& state voting

fiscal conditions \& level of financial wealth of municipality

community consideration: importance and need for a fire station in the eyes of the municipality \& community

possibility of expansion, flexibility, future requirements

pyramid of age, responsiveness \& mobility

density per km2

anticipate significant demographic growth (3 to 10 years) availability and recruitment of candidates

intervention hazards \& impact on polluting the environment (water, air, soil, etc.)

intervention hazards \& effects affecting the health of participants (firefighters, police, ambulance. etc.) and other persons involved

utilization rate for all M\&E

increase in number of services to population vs. money spent on infrastructure \& M\&E

usage for other municipal functions (offices, garage, storage, etc.)

volunteers vs. professionals: in-house training programs \& ECAB official courses, aptitude tests, strengths \& endurance tests, etc.

level and quality of services

disruptions: natural disaster or man-made - reliability of the facility \& M\&E, reliability of services provided

flexibility of the decision under the uncertainty of the environment (fire development as disruption in the original state of the event) 
61

6.5 Sustainability

6.5.1 sustainability sustainable fire station (facility location, energy \& water conservation, green building \& infrastructure, etc.). fire safety and sustainable fire stations often share common goals, but sometimes appear to conflict with each other.

\section{APPENDIX 3}

Table 10. Evaluation of scenarios (A: criterion number, B: category multiply, C: criterion weight, D: normalized weight, 1 to 5 : scenarios)

\begin{tabular}{|c|c|c|c|c|c|c|c|c|}
\hline $\mathbf{A}$ & $\mathbf{B}$ & $\mathbf{C}$ & $\mathbf{D}$ & $\mathbf{1}$ & $\mathbf{2}$ & $\mathbf{3}$ & $\mathbf{4}$ & $\mathbf{5}$ \\
\hline $\mathbf{1}$ & 15 & 3 & 0.01184 & 1 & 1 & 1 & 2 & 1 \\
\hline $\mathbf{2}$ & 15 & 5 & 0.01974 & 0 & 1 & 2 & 1 & 0 \\
\hline $\mathbf{3}$ & 15 & 2 & 0.00789 & -1 & 2 & 2 & -1 & 0 \\
\hline $\mathbf{4}$ & 15 & 3 & 0.01184 & 2 & 1 & 1 & 2 & 1 \\
\hline $\mathbf{5}$ & 15 & 3 & 0.01184 & 2 & 1 & 2 & 1 & 1 \\
\hline $\mathbf{6}$ & 15 & 4 & 0.01579 & 2 & 1 & 2 & 2 & 1 \\
\hline $\mathbf{7}$ & 15 & 5 & 0.01974 & 1 & 1 & 2 & 2 & 1 \\
\hline $\mathbf{8}$ & 10 & 3 & 0.00789 & 1 & 2 & 2 & 0 & 0 \\
\hline $\mathbf{9}$ & 10 & 4 & 0.01053 & 0 & 2 & 2 & 2 & 2 \\
\hline $\mathbf{1 0}$ & 10 & 2 & 0.00526 & 2 & 1 & 1 & 1 & 0 \\
\hline $\mathbf{1 1}$ & 10 & 3 & 0.00789 & 0 & 0 & 1 & 2 & 2 \\
\hline $\mathbf{1 2}$ & 10 & 3 & 0.00789 & 2 & 2 & 2 & 2 & 1 \\
\hline $\mathbf{1 3}$ & 10 & 3 & 0.00789 & -1 & -1 & -1 & -1 & -1 \\
\hline $\mathbf{1 4}$ & 10 & 3 & 0.00789 & 0 & 0 & 0 & 0 & 0 \\
\hline $\mathbf{1 5}$ & 10 & 4 & 0.01053 & 0 & 0 & 0 & 0 & 0 \\
\hline $\mathbf{1 6}$ & 10 & 3 & 0.00789 & 0 & 0 & 0 & 0 & 0 \\
\hline $\mathbf{1 7}$ & 10 & 4 & 0.01053 & 1 & 1 & 2 & 2 & 1 \\
\hline $\mathbf{1 8}$ & 10 & 3 & 0.00789 & 1 & 1 & 2 & 2 & 1 \\
\hline $\mathbf{1 9}$ & 10 & 2 & 0.00526 & 2 & 1 & 2 & 2 & 1 \\
\hline $\mathbf{2 0}$ & 10 & 4 & 0.01053 & 2 & 0 & 2 & 2 & 2 \\
\hline $\mathbf{2 1}$ & 10 & 3 & 0.00789 & 2 & 2 & 2 & 0 & 1 \\
\hline $\mathbf{2 2}$ & 25 & 4 & 0.02632 & -1 & 0 & -1 & 2 & 0 \\
\hline $\mathbf{2 3}$ & 25 & 4 & 0.02632 & 1 & 0 & -1 & 1 & 0 \\
\hline $\mathbf{2 4}$ & 25 & 4 & 0.02632 & 2 & 0 & 0 & 2 & 0 \\
\hline $\mathbf{2 5}$ & 25 & 4 & 0.02632 & -1 & 1 & 2 & 2 & 2 \\
\hline $\mathbf{2 6}$ & 25 & 2 & 0.01316 & -1 & 1 & 0 & 1 & 0 \\
\hline $\mathbf{2 7}$ & 25 & 2 & 0.01316 & 2 & 2 & 2 & 1 & 0 \\
\hline $\mathbf{2 8}$ & 25 & 5 & 0.03289 & 1 & 0 & -1 & 2 & 1 \\
\hline $\mathbf{2 9}$ & 25 & 5 & 0.03289 & 0 & 0 & -1 & 1 & 0 \\
\hline $\mathbf{3 0}$ & 25 & 5 & 0.03289 & 0 & 1 & 0 & 2 & 1 \\
\hline $\mathbf{3 1}$ & 25 & 4 & 0.02632 & 0 & 1 & 1 & 1 & 1 \\
\hline
\end{tabular}

\begin{tabular}{|c|c|c|c|c|c|c|c|c|}
\hline $\mathbf{A}$ & $\mathbf{B}$ & $\mathbf{C}$ & $\mathbf{D}$ & $\mathbf{1}$ & $\mathbf{2}$ & $\mathbf{3}$ & $\mathbf{4}$ & $\mathbf{5}$ \\
\hline $\mathbf{3 2}$ & 25 & 3 & 0.01974 & 0 & 0 & 0 & 0 & 0 \\
\hline $\mathbf{3 3}$ & 25 & 5 & 0.03289 & 2 & 0 & 0 & 1 & 0 \\
\hline $\mathbf{3 4}$ & 25 & 4 & 0.02632 & 0 & 1 & 3 & 3 & 1 \\
\hline $\mathbf{3 5}$ & 25 & 5 & 0.0389 & 1 & 1 & 1 & 1 & 1 \\
\hline $\mathbf{3 6}$ & 25 & 0 & 0.00000 & 0 & 0 & 0 & 0 & 0 \\
\hline $\mathbf{3 7}$ & 25 & 2 & 0.01316 & 1 & 1 & 1 & 1 & 1 \\
\hline $\mathbf{3 8}$ & 15 & 2 & 0.00789 & -2 & 2 & 2 & 2 & 2 \\
\hline $\mathbf{3 9}$ & 15 & 4 & 0.01579 & -2 & 2 & 2 & 2 & 2 \\
\hline $\mathbf{4 0}$ & 15 & 4 & 0.01579 & -2 & 2 & 2 & 2 & 2 \\
\hline $\mathbf{4 1}$ & 15 & 5 & 0.01974 & -2 & 0 & 1 & 2 & 0 \\
\hline $\mathbf{4 2}$ & 15 & 5 & 0.01974 & -2 & 0 & 1 & 2 & 0 \\
\hline $\mathbf{4 3}$ & 15 & 3 & 0.01184 & -1 & 1 & 0 & 0 & 0 \\
\hline $\mathbf{4 4}$ & 15 & 4 & 0.01579 & -1 & 1 & 0 & 0 & 0 \\
\hline $\mathbf{4 5}$ & 15 & 3 & 0.01184 & 0 & 0 & 0 & 0 & 0 \\
\hline $\mathbf{4 6}$ & 20 & 4 & 0.02105 & -2 & 0 & -1 & 1 & 0 \\
\hline $\mathbf{4 7}$ & 20 & 3 & 0.01579 & -2 & 1 & 1 & 2 & 1 \\
\hline $\mathbf{4 8}$ & 20 & 4 & 0.02105 & 2 & 2 & 2 & 2 & 2 \\
\hline $\mathbf{4 9}$ & 20 & 5 & 0.02632 & 2 & 1 & 1 & 1 & 1 \\
\hline $\mathbf{5 0}$ & 20 & 5 & 0.02632 & 2 & 2 & 2 & 2 & 2 \\
\hline $\mathbf{5 1}$ & 20 & 3 & 0.01579 & -1 & 2 & 2 & 2 & 2 \\
\hline $\mathbf{5 2}$ & 20 & 4 & 0.02105 & 0 & 0 & -1 & 2 & 0 \\
\hline $\mathbf{5 3}$ & 20 & 5 & 0.02632 & 0 & 0 & -1 & 2 & 0 \\
\hline $\mathbf{5 4}$ & 20 & 3 & 0.01579 & 0 & 1 & 2 & 2 & 1 \\
\hline $\mathbf{5 5}$ & 20 & 3 & 0.01579 & 0 & 0 & 0 & 1 & 0 \\
\hline $\mathbf{5 6}$ & 20 & 1 & 0.00526 & 0 & 0 & 0 & 0 & 0 \\
\hline $\mathbf{5 7}$ & 15 & 4 & 0.01579 & -1 & 0 & 1 & 2 & 0 \\
\hline $\mathbf{5 8}$ & 15 & 4 & 0.01579 & -2 & 1 & 1 & 2 & 1 \\
\hline $\mathbf{5 9}$ & 15 & 4 & 0.01579 & 0 & 1 & 1 & 2 & 1 \\
\hline $\mathbf{6 0}$ & 15 & 3 & 0.01184 & -1 & 0 & -1 & 1 & 0 \\
\hline $\mathbf{6 1}$ & 15 & 4 & 0.01579 & -1 & 1 & 2 & 2 & 1 \\
\hline
\end{tabular}

